
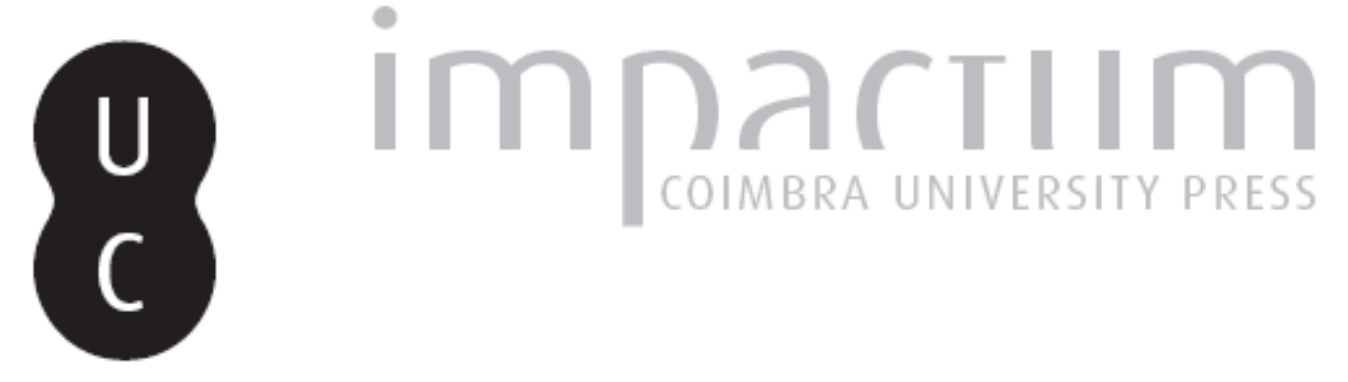

\title{
Contributo para o estudo das relações entre a Historiografia e a sátira menipeia
}

Autor(es): $\quad$ Ferreira, Paulo Sérgio Margarido

Publicado por: Centro de História da Universidade de Lisboa

URL persistente:

URI:http://hdl.handle.net/10316.2/23842

DOI:

DOI:http://dx.doi.org/10.14195/0871-9527_18_10

Accessed : $\quad$ 26-Apr-2023 11:36:29

A navegação consulta e descarregamento dos títulos inseridos nas Bibliotecas Digitais UC Digitalis, UC Pombalina e UC Impactum, pressupõem a aceitação plena e sem reservas dos Termos e Condições de Uso destas Bibliotecas Digitais, disponíveis em https://digitalis.uc.pt/pt-pt/termos.

Conforme exposto nos referidos Termos e Condições de Uso, o descarregamento de títulos de acesso restrito requer uma licença válida de autorização devendo o utilizador aceder ao(s) documento(s) a partir de um endereço de IP da instituição detentora da supramencionada licença.

Ao utilizador é apenas permitido o descarregamento para uso pessoal, pelo que o emprego do(s) título(s) descarregado(s) para outro fim, designadamente comercial, carece de autorização do respetivo autor ou editor da obra.

Na medida em que todas as obras da UC Digitalis se encontram protegidas pelo Código do Direito de Autor e Direitos Conexos e demais legislação aplicável, toda a cópia, parcial ou total, deste documento, nos casos em que é legalmente admitida, deverá conter ou fazer-se acompanhar por este aviso.

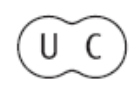



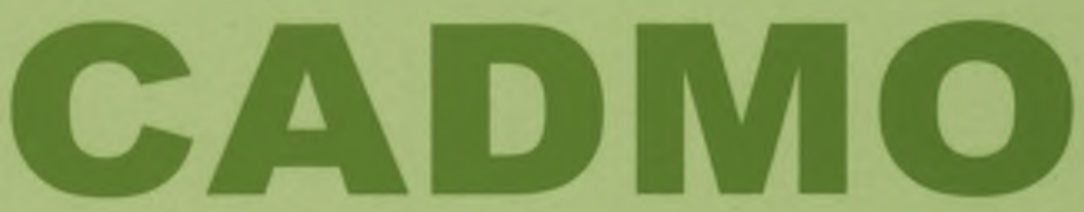

Revista de História Antiga

\author{
Centro de História \\ da Universidade de Lisboa
}

18

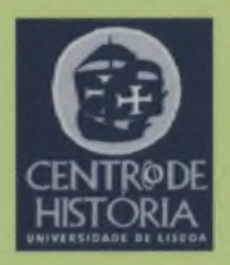

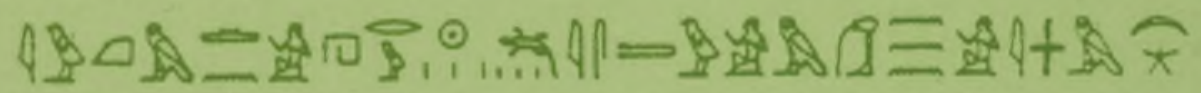

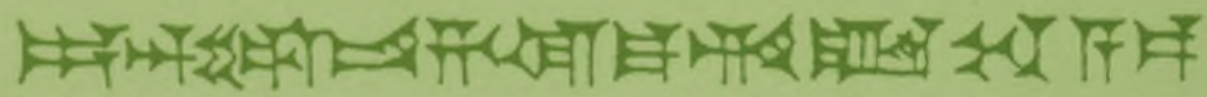

MHNIN AEI $\Delta$ E $\Theta E A ~ \Pi H \Lambda H I A \triangle E \Omega$ 


\title{
CONTRIBUTO PARA O ESTUDO DAS RELAÇÕES ENTRE A HISTORIOGRAFIA E A SÁTIRA MENIPEIA
}

\author{
PAULO SÉRGIO MARGARIDO FERREIRA \\ Universidade de Coimbra \\ paulusergius@yahoo.com
}

\section{Resumo}

A partir de um cauteloso confronto entre, de um lado, a historiografia e a obra de Suetónio, e, do outro, as Saturae Menippeae de Varrão e a Diui Claudii Apocolocyntosis de Séneca, procura este estudo realçar o uso, por parte das duas últimas obras referidas, dos exemplos mais virtuosos e de visões algo idílicas do passado, para criticar a decadência presente. Por vezes, exagera a menipeia na descrição dos aspectos negativos do passado, para manifestar a sua esperança no futuro. Ainda se interroga sobre a eficácia prática da sua mensagem. É, no entanto, através da sua vertente moralizante que complementa a leitura que a história faz dos feitos que, em determinado momento e em determinada sociedade, considera mais importantes.

Palavras-chave: sátira menipeia; historiografia; spoudaia; geloion; Varrão; Séneca; Apocolocyntosis; caricatura.

\begin{abstract}
Starting with a cautious confrontation between, on the one hand, the history and Suetonius' work, and, on the other hand, Varro's Saturae Menippeae and the Diui Claudii Apocolocyntosis by Seneca, this study aims to emphasise the use in the works referred to of the most virtuous examples and of somewhat idyllic visions of the past, in order to criticise the present decay. Sometimes, the Menippean satire exaggerates in describing the negative aspects of
\end{abstract}


the past with the purpose of manifesting some hope in the future. It still questions about the practical effects of his message. However it's through its moralising that tendency the Menippean satire complements history's interpretation of the facts that, in a given time and society, considers the most important ones.

Keywords: Menippean satire; history; spoudaia; geloion; Varro; Seneca; Apocolocyntosis; caricature.

No propósito de distinguir a poesia da História, sustenta Aristóteles, em Po. 9. $1451^{\text {a }} 36$ ss., que, enquanto a segunda descreve o que sucedeu e, por conseguinte, se atém ao particular, já a primeira incide no que, de acordo com a necessidade e a verosimilhança, poderia suceder, e, consequentemente, tem por alvo o universal. Se, contudo, atentarmos nos escritos dos logógrafos ou, no dizer de Heródoto 2.134, 143 , dos logopoioi "contadores de histórias", verificamos que tanto escrevem sobre deuses como sobre heróis, que tanto professam oferecer a verdadeira e a correcta versão de um mito como de um facto efectivamente ocorrido. Assim se justifica a invencível renitência dos modernos investigadores na atribuição do título de historiadores aos predecessores de Heródoto. Ao considerarmos respectivamente, porém, os mitos fundacionais gregos ou as lendas romanas nas obras de Heródoto e de Tito Lívio, damos conta de que, pelo menos momentaneamente, os historiadores suspendem ou relegam para segundo plano a descrença, em prol de uma exaltação dos primórdios das cidades ou do carácter exemplar e edificante dos mitos.

Uma vez que, da obra de Menipo, insignificante é o que subsiste, resta o recurso a depoimentos posteriores, mais ou menos anedóticos e ficcionalizados, nomeadamente de Diógenes Laércio 99-101 e, entre outros, Luciano, em Icaromenippus, Necyomantia e Dialogi mortuorum, para a reconstituição, a partir de dados biográficos, dos primórdios da sátira menipeia. Contrariamente, porém, ao que sucedia na relação entre a historiografia e os mitos fundacionais, não se depreende, das informações subsistentes acerca do natural de Gádara, qualquer comportamento exemplar ou ensinamento edificante.

Do mesmo modo que, em Po. 4.1448 34 -38, Aristóteles apenas admite uma oposição entre as spoudaia "obras elevadas" e o geloion «ridículo", que se revela limitativa quando se trata de definir a sátira menipeia, assim o alvo deste género é algo que funde História e poesia 
de um modo que, por motivos de ordem espacial e temporal, não aparece contemplado pela reflexão aristotélica.

É certo que o termo satura começou por ser o feminino do adjectivo satur "cheio" e caracterizar o substantivo lanx 'travessa', no que seria uma baixela com diversos tipos de primícias; ou começou por designar uma mistura de enchidos ou salsicha. Por extensão, passou a denotar um género que combinava temas, como as fábulas animais, a censura moral, o diálogo ético e a autoconsciente presença autoral, com técnicas paródicas, de exagero, de esvaziamento e caricaturais. A este redimensionamento do conceito não será seguramente alheio o início da circulação de uma falsa etimologia que relacionava o termo com os satyri "sátiros", os companheiros de Dioniso que costumavam participar no drama satírico.

Ora, baseado no contraste entre uma concepção de sátira que implica necessariamente uma crítica construtiva por parte da instancia enunciativa e o carácter nada exemplar da vida de Menipo, classificou J. C. Relihan de oximórico o título varroniano Saturae Menippeae.(1) À luz, no entanto, da moderna teoria de K. Kuiper, segundo a qual a sátira se não define exclusivamente pela forma ou pela função ou por ambas, mas pelo modo como o perceiver apreende cada uma delas ou as duas;(2) tendo ainda em conta a maior proximidade temporal entre Varrão e Menipo, vale, seguramente, a pena conceder maior crédito ao juízo do perceiver Varrão do que ao de Relihan.

Embora, mencionados os quatro tipos de ficção (novel, confession, anatomy e romance), sustente $\mathrm{N}$. Frye que a anatomy, vulgarmente conhecida como sátira menipeia ou varroniana e geralmente centrada nas atitudes mentais das personagens, retrata ideias abstractas e teorias, e estiliza personagens que não passam de «mouthpieces of the ideas they represent, ${ }^{(3)}$ a verdade é que o crítico não deixa de reconhecer a presença, na anatomy, de temas como as descompensações, as obsessões mentais e, entre outros vícios sociais, o pedantismo e o pretensiosismo filosóficos. De igual sorte, se, entre as catorze características da ménippée referidas por M. Bachtin, encontramos uma que consiste na libertação das limitações históricas, das exigências de verosimilhança, e na "liberté exceptionnelle de l'invention philosophique et thématique» (4); a verdade é que o tipo referido também costuma optar pela actualidade sociopolítica, que Ihe confere uma dimensão jornalistique ${ }^{(5)}$, no tratamento das ideias do momento. Do exposto resulta, em suma, claro que, além da dimensão fantástica, contém a sátira menipeia uma vertente crítica e moralizante, que, em contraste 
com, e.g., o carácter «intramural» da paródia, a define, bem como à sátira em verso tradicional e ao modo satírico, como "extramural».(6) É precisamente no pressuposto de um referencial histórico ou de uma consciência ou opinião pública relativamente a esse referencial que coincidem a historiografia e a sátira menipeia. Dada, no entanto, a natureza arbitrária da relação entre referente, significante e significado, a diferença está no modo como esse referente histórico aparece linguística e literariamente representado; e no propósito que está subjacente a essa representação e, sobretudo, no modo como ambos são apreendidos pelos perceivers.

Ora a vertente moralizante da sátira menipeia manifesta-se frequentemente na apresentação de um paradigma positivo que contrasta com a situação criticada. Assim, dos fragmentos subsistentes dos Aborigines varronianos, é possível depreender o contraste entre, de um lado, o modo de vida, de acordo com a natureza, dos povos autóctones e pré-históricos instalados na região do Lácio, mais propriamente em Reate, e, do outro, o dos contemporâneos de Varrão e, ao cabo, os malefícios da civilização. No Bimarcus, depois da crítica aos magistrados que abusivamente utilizam, em proveito próprio, os recursos do estado, mais concretamente os militares, e dão, aos cidadãos livres que comandam, trabalhos habitualmente feitos por escravos; e de uma eventual invectiva contra o luxo das habitações e a avareza dos poderosos [frg. XIV, 58 (66) Cèbe]; após, entre outras admoestações, a dirigida ao general concussionário que, para decorar a sua casa, pilha os aliados e saqueia os territórios conquistados [frg. XV, 59 (64) Cèbe], uma entidade enunciativa contrapõe:

Aui et ataui nostri, cum alium ac cepe olerent, tamen optume animati erant. .7) $^{2}$

"Os nossos avós e bisavós, embora cheirassem a alho e a cebola, tinham um grande coração.»

Por vezes, encontramos, nas Menippeae, referências, em moldes muito semelhantes aos da historiografia, a factos históricos: ao recordar, no frg. XV, 195 (195) Cèbe do Gerontodidaskalos, o caso do cônsul Mânio Cúrio Dentato, que, ao fazer um recrutamento de tropas no Capitólio e ao deparar com a falta de comparência à convocatória de um membro da sua tribo, o vendeu, Varrão presta homenagem à dedicação abnegada dos magistrados do passado, em termos muito próximos dos de Tito Lívio, em Periochae (Epit.) 14, ou dos de Valério Máximo 6.3.4. 
Nem sempre o passado exemplar dista tanto do presente: no Sesqueulixes, e.g., é seguramente o próprio Varrão quem, para demonstrar que sofreu e aprendeu mais do que o Ulisses homérico, recorda, em registo autobiográfico, as suas viagens e os principais episódios da sua carreira, e estabelece uma amarga comparação entre a cidade que deixara e a que volta a encontrar [frgs. XIX, 478 (475) - XXIII, 482 (482) Cèbe].

O contraste entre o passado e o presente manifesta-se, no plano sintagmático, na oposição entre tum e nunc. Um dos exemplos porventura mais significativos desta estruturação discursiva ocorre no frg. V, 489 (488) Cèbe do Sexagesis, onde se pode ler:

ergo tum Romae parce pureque pudentis / uixere; en patriam! Nunc sumus in rutuba.

«Portanto viveram então em Roma parcimoniosa e virtuosamente / no pudor; olha para a pátria! Agora estamos no caos."

No intuito de justificar a inclusão das lendas em $A b$ Vrbe condita, haveria Tito Lívio de escrever (I, praef. 7 e 10-11):

Datur haec uenia antiquitati ut miscendo humana diuinis primordia urbium augustiora faciat....

Hoc illud est praecipue in cognitione rerum salubre ac frugiferum, omnis te exempli documenta in inlustri posita monumento intueri; inde tibi tuaeque rei publicae quod imitere capias, inde foedum inceptu foedum exitu quod uites. Ceterum aut me amor negotii suscepti fallit, aut nulla unquam res publica nec maior nec sanctior nec bonis exemplis ditior fuit, nec in quam ciuitatem tam serae auaritia luxuriaque immigrauerint, nec ubi tantus ac tam diu paupertati ac parsimoniae honos fuerit.

«À antiguidade dá-se a vénia para tornar mais augustos os primórdios das cidades pela mistura do humano com o divino....

O que há de mais salutar e fecundo no estudo da história é que se contemplam os ensinamentos de toda a espécie de exemplos dispostos num momento bem visível; daí se podem extrair modelos a imitar para uso próprio e do seu país, e actos vergonhosos a evitar pelas suas causas ou pelas suas consequências. De resto, ou o entusiasmo pela minha empresa me ilude, ou jamais algum país foi maior, mais puro, mais rico em bons exemplos nem levaram tanto tempo a entrar numa cidade a avareza e o luxo, nem a tal ponto nem durante tanto tempo a pobreza e a parcimónia ocuparam lugar de honra.»(8) 
Em suma: ao situar, no passado, os exemplos de vida virtuosa, o laudator temporis acti adopta, perante essa realidade, uma atitude semelhante, p. ex., à de Tito Lívio relativamente às lendas que ilustram as virtudes que configuram o mos maiorum romanos, mas, ao contrário deste historiador, esquece os maus exemplos do passado.

Ainda que justificado pelo próprio contexto histórico, o narrador da Diui Claudii Apocolocyntosis, de Séneca, inverte a habitual valorização relativa de ambos os tempos, e, em claro contraponto com a má governação de um passado recente, deposita, no presente e no futuro romanos, a esperança em uma nova era de justiça social e de felicidade. É o que se depreende das suas palavras iniciais:

Quid actum sit in caelo ante diem III idus Octobris anno nouo, initio saeculi felicissimi, uolo memoriae tradere. ${ }^{(9)}$

"Quero registar para a posteridade o que sucedeu no céu a treze de Outubro do ano novo que marcou o início de uma era de prosperidade.»

Subjacente ao passo está, por conseguinte, o regozijo do narrador com a morte de Cláudio e com a perspectiva de uma nova idade do ouro que a subida de Nero ao trono representa.

Além, no entanto, de julgar o passado recente à luz do presente, Séneca reserva para o diuus Augustus a recordação de um passado mais distante e, ao cabo, de um principado artificiosa e tendenciosamente exemplar, com o propósito de revestir o Pater Patriae de uma autoridade que torne decisiva, para a deliberação final, a sua intervenção condenatória de Cláudio (Apoc. 10).

Sem a importância e a cultura de um Augusto, o liberto Ganimedes encarna, em Petr. 44, o papel de um laudator temporis acti que, pelas banalidades que diz, se deixa cair no ridículo. Trata-se, por conseguinte, de estender aos libertos a estratégia frequentemente utilizada por Petrónio, no Satyricon, para desautorizar as tiradas moralistas dos scholastici.

Quer isto dizer que, se a sátira menipeia é capaz de invocar, por vezes em visões parciais da história, os melhores exemplos do passado para criticar o presente, a verdade é que também sabe ser suficientemente autocrítica para ter consciência de que o que apregoa não passa, para o vulgo romano e para a maior parte de scholastici e aristocratas, de retórica, sem consequências práticas na vida do quotidiano.

Além de levar a sátira menipeia a procurar, na historiografia, pontos de referência para avaliar o presente, a ligação do modo literário à 
realidade é o ponto de partida para o recurso a processos de deformação caricatural dessa realidade e de paródia das formas de representação "realista" dos factos. É, por conseguinte, no âmbito desta segunda prática que se deve entender a repetição com distanciamento crítico, no início da Apocolocyntosis, da estrutura dos prefácios dos historiadores. Assim, o teor das palavras citadas de Séneca não difere substancialmente dos propósitos enunciados por Heródoto, no prólogo das suas Historiae:

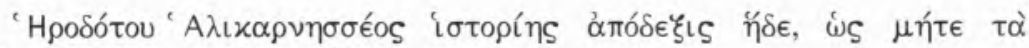

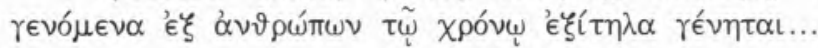

«Esta é a exposição das informações de Heródoto de Halicarnasso, a fim de que os feitos dos homens, com o tempo, se não apaguem....”(10)

Como nos prólogos historiográficos, professa o narrador senequiano, em seguida, a sua imparcialidade (Apoc. 1):

Nihil nec offensae nec gratiae dabitur. Haec ita uera.

«Nada será ditado pela ofensa ou pelo favor. Isto é a pura verdade.»

Este tópico encontra-se, e.g., em Tácito, Hist. 1.1:

Mihi Galba Otho Vitellius nec beneficio nec iniuria cogniti.

Dignitatem nostram a Vespasiano inchoatam a Tito auctam, a Domitiano longius prouectam non abnuerim: sed incorruptam fidem professis neque amore quisquam et sine odio dicendus est. ${ }^{(11)}$

«Para mim, Galba, Otão e Vitélio não se fazem conhecer por benefício algum ou ofensa alguma.

A carreira das honras foi-me aberta por Vespasiano, Tito me fez progredir, Domiciano me fez avançar ainda mais, não o ouso negar; mas quem fez votos incorruptíveis de fidedignidade deve falar de cada um sem amor e sem ódio.”

Por fim, comporta o prólogo historiográfico uma referência às fontes, que o narrador senequiano converte numa alusão paródica aos iuratores e a Lívio Gemínio ou Gemino (Apoc. 1.2). ${ }^{(12)}$ É que, conforme explica Eden ad loc., os iuratores eram funcionários civis menores que tinham o encargo de reunir, num census, os prometidos retornos de activos taxáveis e outros débitos financeiros particulares (cf. Plauto, Trin. 872 e Poen. 55ss., e Lívio 39.44.2). Ao contrário, porém, 
do que sucedia com este funcionário, costumava o historiador dispensar de juramento todas as suas fontes.

De igual sorte e no que será uma espécie de paródia à distinção aristotélica entre poesia e história, haveria Eumolpo, em Petr. 118.6, de dizer que, na poesia, se deve deixar correr livremente a inspiração, de modo a inventar mil peripécias e intervenções divinas, e a jogar com o estilo, para que a obra se ajuste mais a um espírito demente quam religiosae orationis sub testibus fides, "do que a um relato escrupuloso atestado pelas fontes»(13). Quanto a Lívio Gemínio ou Gemino, foi um Appiae viae curator a quem Calígula obrigara a testemunhar que vira a irmã e amante do imperador, Júlia Drusila, depois de morta, subir ao céu (Díon 59.11.4). Embora Lívia, com o propósito de deificar Augusto, tenha incumbido do mesmo um certo Numério Ático (Díon 56.46.2, e Suetónio, Aug. 100.4), a verdade é que do facto, pelas razões já aduzidas, se não encontra qualquer eco na Apocolocyntosis.

Mas nem precisa o leitor de esperar pela apresentação da fonte, para começar a suspeitar da credibilidade do informante e do próprio narrador senequiano: além de já ter dado a entender, no mínimo, a sua antipatia pelo falecido, e ter indiciado o carácter parcial do seu relato, ainda observara:

Si quis quaesiuerit unde sciam, primum, si noluero, non respondebo.

"Se alguém perguntar de onde me vem a informação, em primeiro lugar, se não quiser, não responderei.»

Depois de dizer que Cláudio ilustra bem o provérbio segundo o qual cada um deveria nascer louco ou rei, o narrador ainda afirma de forma irreverente:

si libuerit respondere, dicam quod mihi in buccam uenerit.

"Se me apetecer responder, direi o que me vier à cabeça."

Do ponto de vista estilístico, o uso da forma popular e coloquial buccam contribui ainda mais para o descrédito da instância enunciativa.

O capítulo de abertura da Apocolocyntosis prepara o leitor para a vertente caricatural da obra: é sabido que, ao caminhar, Cláudio se sentia traído pela debilidade dos jarretes (Suetónio, Cl. 30: ingredientem destituebant poplites minus firmi $\left.{ }^{(14)}\right)$, mas a comparação do andar do falecido ao de lulo, quando tenta acompanhar o pai na fuga de Tróia (Apoc. 1.2 cit. n. 12, e Virgílio, A. 2.723s.), ou a referência, em 5.2 e 
em sinal de mau omen (cf. Virgílio, A. 8.302, e Horácio, Ep. 2.2.37), ao facto de arrastar a direita e, por conseguinte, não poder entrar no Olimpo com o pé correspondente revelam ora exagero, ora uma leitura parcial de um facto, com o propósito de ridiculizar a personagem. É certo que Cláudio abanava involuntariamente a cabeça (Suetónio, Cl. 30: caput cum semper, tum inquantulocumque actu uel maxime tremulum; cf. Díon 60.2.1), mas ver, neste movimento, uma ameaça é exagero caricatural que, conjugado com o que passa por considerar ininteligível o grego do falecido (cf. Suetónio, Cl. 4.6 e 30), prepara um dos pontos altos da caricatura de Cláudio e da do próprio Hércules: ao ver o primeiro, teme o segundo a possibilidade de estar perante o seu décimo terceiro trabalho (Apoc. 5.3). Convém ter, no entanto, presente que a crítica ao pretensiosismo filológico e filosófico se constituiu, desde muito cedo, como uma das características mais marcantes da menipeia.

À boa maneira menipeia, aproveita Séneca a caricatura da realidade para revelar o seu cepticismo relativamente aos deuses míticos do tradicional panteão greco-latino. Não é, de resto, por acaso que, ao contrário do que sucede com o Pater lanus ou com Diespiter, Augusto, um humano deificado, é a única divindade da obra ficcionalmente imaculada. Está, de resto, em sintonia com um Deorum concilium que funciona segundo as tradicionais regras que presidem às sessões do Senado romano.

Do exposto, parece-me, em suma, legítimo concluir que, quer quando, em contraste com a decadência do presente, invoca os bons exemplos do passado; quer quando critica o passado e revela uma eufórica confiança no presente e no futuro; quer quando manifesta amarga e irónica consciência da surdez da sociedade em geral aos seus apelos moralizantes, a sátira menipeia, ora género com existência autónoma, ora modo que se esconde sob a estrutura geral de outros géneros, complementa, na sua vertente moralizante, a visão da historiografia, com um retrato exagerado e cómico de comportamentos e de indivíduos que, para o historiador, não têm grande interesse, mas que se revelam imprescindíveis para a compreensão do sentir do homem de cada época. E se a distância que separa a realidade da perspectiva crítica e deformada que, por vezes, dela veicula Suetónio, nas suas Vitae Caesarum, prepara o romance histórico, que dizer da influência, no romance carnavalesco e no moderno, da uma sátira menipeia tão centrada nas pequenas coisas do quotidiano e no sentir problemático do homem seu contemporâneo? 


\section{Notas}

(1) Joel C. RELIHAN, Ancient Menippean Satire, Baltimore and London, 1993, 41.

(2) Koenraad KUIPER, "The nature of satire", Poetics 13, 1984, 459-473, esp. 459. Importa, no entanto, ter presente que é Aulo Gélio quem, em 2.18.7, informa: Ex quibus ille Menippus fuit cuius libros M. Varro in satiris aemulatus est, quas alii 'Cynicas', ipse appellat 'Menippeas'. Cito a partir de AULU-GELLE, Les nuits Attiques, Livres I-IV, texte établi et traduit par René MARACHE. Paris, 1967, 108.

(3) Northrop FRYE, Anatomy of criticism. Four essays, Princeton, New Jersey, 1957, 309.

(4) Mikhaïl M. BAKHTINE, La poétique de Dostoïevski (trad. de Isabelle Kolitcheff a partir de Problemy poetiki Dostoïevskovo, Moscou, Écrivains soviétiques, $\left.{ }^{2} 1963\right)$. Paris, 1970, 160.

(5) ID. 165.

(6) Os termos da distinção são de Linda HUTCHEON, Uma teoria da paródia (trad. de Teresa Louro Pérez a partir de A Theory of Parody, London, 1985), Lisboa, 1989, 61.

(7) Frg. XXV, 69 (63) Cèbe. Todas as citações de Varrão seguem a lição de VARRON, Satires Ménippées, vols. 1-13, édition, traduction et commentaire par Jean-Pièrre CĖBE, Roma, 1972-1999. O passo citado encontra-se no vol. 2, 1974, 202. A oposição entre o passado virtuoso e o presente degradado é recorrente nas Menippeae de Varrão: nos frgs. IV, 9 (11) e V, 10 (10) Cèbe do Agatho, recorda a instância enunciativa, no âmbito de uma reflexão que defende o casamento tradicional e critica a paixão amorosa, que os antepassados latinos não queriam que uma moça, antes de ser núbil, participasse em banquetes, de modo a ficar com os ouvidos cheios de palavras de Vénus; e que só com fesceninos de propósitos obscenos, podiam os rapazes abrir os ouvidos da recém-casada. Embora MERCKLIN, referido por Cèbe, op. cit. 45, afirme que o Agatho seria um logistoricus, E. BOLISANI, também citado por Cèbe, ibidem, invoca a mistura de sério e de cómico, bem como a forma poética de certos fragmentos, para refutar aquela hipótese. No frg. 181 (181) Cèbe do Gerontodidaskalos, a instância enunciativa recorda a sacralidade, a religiosidade e a pureza dos tempos antigos; nos frgs. VI, 186 (196) e VII, 187 (187) Cèbe, pergunta retoricamente quantas vezes costumava um priscus homo ac rusticus Romanus fazer a barba no espaço de nove dias que mediavam entre dois mercados, e afirma que, só casado, desnudava o jovem a cintura de uma mulher; no frg. X, 190 (190) Cèbe, recorda, em contraste com os gostos refinados e os flirts das mulheres fáceis do seu tempo [frgs. XI, 191 (191) e XII, 192 (192) Cèbe], os afazeres da matrona romana ideal; e, no frg. XVII, 197 (197) Cèbe, fala de alguém que se trespassou com um cutelo de cozinha, pois ainda se não tinham importado da Bitínia cutelos ornados de incrustações metálicas. O falecimento de um parente próximo de Varrão [frgs. I, 247 (258) e II 248 (257) Cèbe] seria, na reconstituição que Cèbe faz do Manius, um pretexto para a descoberta, no buraco do falecido, de um cofre com livros [frg. III, 249 (255) Cèbe], que se levariam a Varrão [frg. IV, 250 (256) Cèbe], que, por sua vez, revelaria o seu conteúdo a Mânio, que se encarregaria de reunir os concidadãos no foro [frg. V, 251 (259) Cèbe], para elogiar a conduta virtuosa dos antigos e estigmatizar os costumes contemporâneos. No Sexagessis, retrata Varrão o caso de um homem que adormece com dez anos de idade e acorda cinquenta anos mais tarde. Ao regressar a Roma, nota que tudo está mudado [frg. IV, 488 (491) Cèbe]: nota, com nostalgia e desencanto, que a pietas, a fides e a pudicitia dos tempos antigos tinham dado lugar à impietas, à perfidia e à impudicitia [frg. VI, 490 (495) Cèbe]. Considerada, em contraste com um passado virtuoso, a decadência contemporânea nos planos familiar [frg. VII, 491 (496) Cèbe], público e político [frg. VIII, 492 (497) Cèbe], judicial [frg. IX, 493 (498) e X, 494 (499) Cèbe] e privado [frg. XI, 495 (501) Cèbe], 
alguém interpela Varrão nestes termos [frg. XXI, 505 (505) Cèbe]: "erras", inquit, "Marce; accusare noli: ruminaris antiquitates." "'enganas-te', diz ele, 'Marco; não acuses: tu andas a remoer velharias.'” Estas palavras mostram que Varrão não tinha grandes ilusões quanto aos efeitos práticos da sua crítica moralizante.

(8) Cito a partir de TITE-LIVE, Histoire Romaine, T. I, L. I (texte établi par Jean BAYET) Paris, ${ }^{2} 1971,3$ e 4 . A tradução é de Maria Helena da ROCHA PEREIRA, Romana: antologia da cultura latina, Coimbra, ${ }^{4} 2000,209$.

(9) SENECA, Apocolocyntosis, edited by P. T. EDEN, Cambridge - New York - Port Chester - Melbourne - Sydney, 1984, 28.

(10) HERODOTUS, Books I-II, with an English translation by A. D. GODLEY, Cambridge, Mass. - London, ${ }^{2} 1926$, repr. 1999, 2. Tradução de Maria Helena da ROCHA PEREIRA, Hélade. Antologia da cultura grega, Porto, ${ }^{8} 2003,249$.

(11) Bibliotheca Teubneriana Latina, ${ }^{2} 2002$, moderante Paul Tombeur, München und Leipzig. Cf. Políbio 1.14.6 ss., e Tácito, Ann. 1.1.6: sine ira et studio.

(12) Quis umquam ab historico iuratores exegit? Tamen si necesse fuerit auctorem producere, quaerito ab eo qui Drusillam euntem in caelum uidit: idem Claudium uidisse se dicet iter facientem 'non passibus aequis'. "Quem é que alguma vez exigiu de um historiador testemunhas sob juramento? Se, contudo, for necessário produzir uma fonte, perguntem ao que viu Drusila ir para o céu: esse dirá que viu Cláudio a fazer o mesmo caminho 'com passadas nada iguais'."

(13) PETRONIUS, Satyricon reliquiae, quartum edidit Konrad MUELLER, Stutgardiae et Lipsiae, 1995, 130. PETRÓNIO, Satyricon, versão portuguesa de Delfim F. LEÃO, Lisboa, 2005, 199.

(14) Cf. SUETÓNIO, Cl. 21.6: non si foeda uacillatione discurrens. 